\title{
The Effects of Nusinersen Treatment on Respiratuar Status of Children with Spinal Muscular Atrophy
}

\author{
Evrim Hepkaya $^{1}$, Ayse Ayzit Kilinc ${ }^{2}$, İpek Ülkersoy ${ }^{1}$, Azer Kilic Baskan ${ }^{1}$, Hüseyin Arslan ${ }^{1}$, \\ Özge Meral ${ }^{1}$, Tugce Damla Dilek ${ }^{1}$, Serhat Guler ${ }^{1}$, Sema Saltık ${ }^{1}$, and Haluk Cokugras ${ }^{3}$ \\ ${ }^{1}$ Istanbul University-Cerrahpasa Cerrahpasa Faculty of Medicine \\ ${ }^{2}$ Istanbul University Cerrahpasa Faculty of Medicine \\ ${ }^{3}$ Istanbul Universitesi-Cerrahpasa
}

November 15,2021

\begin{abstract}
Introduction : Pulmonary involvement is the main prognostic factor in children with spinal muscular atrophy (SMA). Nusinersen, a new treatment modality, is being evaluated in recent studies, although the respiratory part has not yet been clarified. We aimed to reveal the effects of nusinersen on the respiratory functions of patients with spinal muscular atrophy (SMA). Methods : In this single-center randomised study, conducted between June 2020/July 2021, patients with SMA were evaluated before and during nusinersen therapy. Data were collected on respiratory status, nutritional support, motor involvement, and other comorbidities that may affect the disease prognosis. Results : Patients with the number of 43 (18 type1, 12 type2, 13 type3) with a mean age of diagnosis of 10 months (range 1.5-192) and 24 months (3-219) at the start of nusinersen therapy were included. An improvement in respiratory status was noted in six patients between the second and third assessment. SMN2 copy numbers were significantly associated with better prognosis. Early initiation of nusinersen was significantly correlated with reduced hospital admissions. Nutritional support and weight gain were remarkable in the ventilatory supported group. A significant improvement was observed in motor functions, and chop-intend scores were statistically significantly higher in non-tracheostomized group $(\mathrm{p}<0.005)$. Conclusion : We think that nusinersen's effect may be significant with early initiation and continuation of treatment. Improvements in respiratory functions noted in our study require to be supported with future long-term studies considering the overall genetic and environmental status, even the cost-effectiveness, to make a global consensus on nusinersen therapy.
\end{abstract}

\section{Hosted file}

Main Document.docx available at https://authorea.com/users/376931/articles/545562-theeffects-of-nusinersen-treatment-on-respiratuar-status-of-children-with-spinal-muscularatrophy

\section{Hosted file}

Table 1.docx available at https://authorea.com/users/376931/articles/545562-the-effects-ofnusinersen-treatment-on-respiratuar-status-of-children-with-spinal-muscular-atrophy

\section{Hosted file}

Table 2.docx available at https://authorea.com/users/376931/articles/545562-the-effects-ofnusinersen-treatment-on-respiratuar-status-of-children-with-spinal-muscular-atrophy

\section{Hosted file}


Table 3.docx available at https://authorea.com/users/376931/articles/545562-the-effects-ofnusinersen-treatment-on-respiratuar-status-of-children-with-spinal-muscular-atrophy

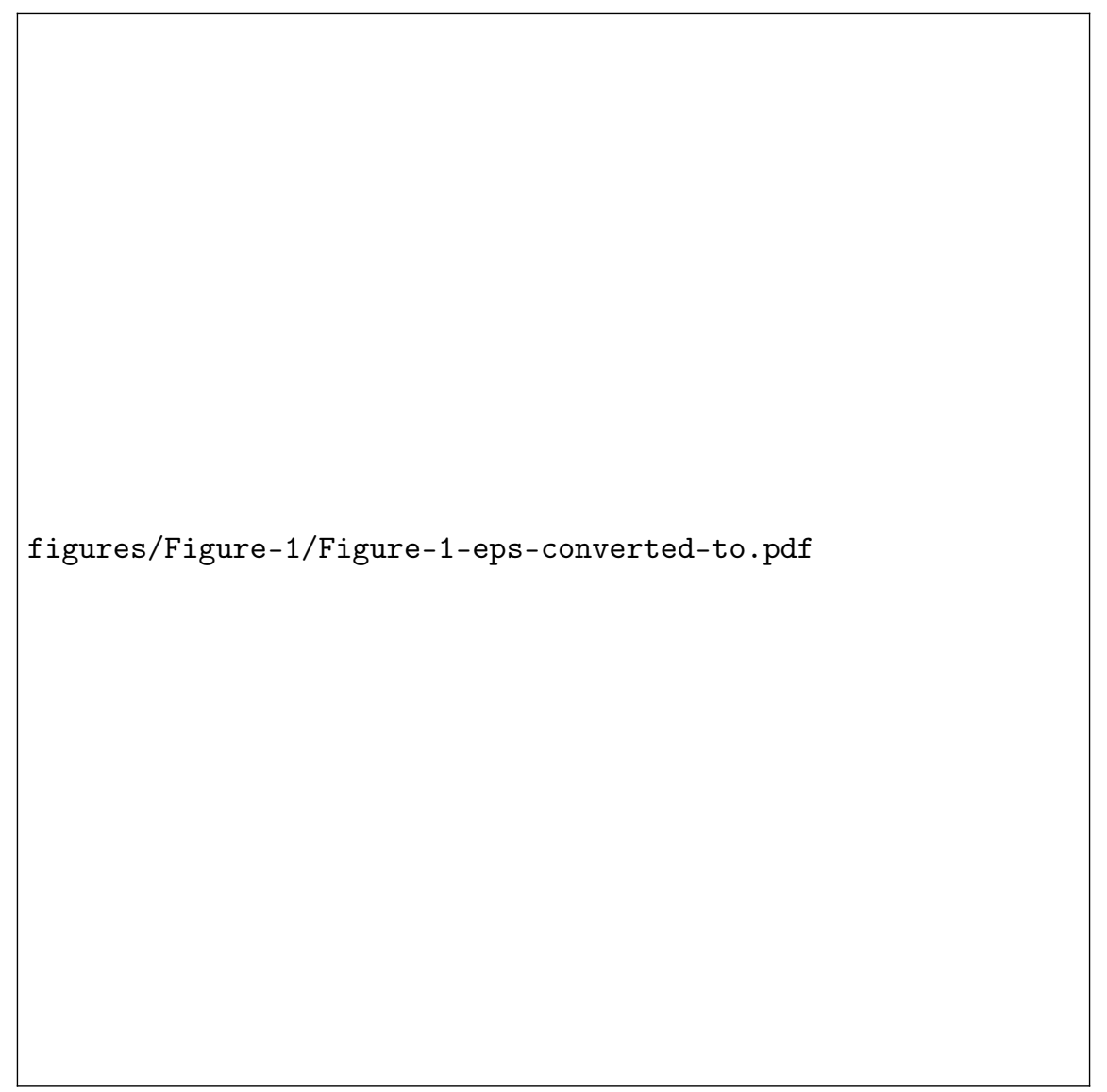


figures/Figure-2/Figure-2-eps-converted-to.pdf 
figures/Figure-3/Figure-3-eps-converted-to.pdf 